\title{
Konsep Pendidikan Islam Mengenai Akhlak Perspektif Al Ghazali (Kajian Kitab Ihya' Ulumuddin)
}

\section{KONSEP PENDIDIKAN ISLAM MENGENAI AKHLAK PERSPEKTIF AL GHAZALI (KAJIAN KITAB IHYA' ULUMUDDIN)}

\author{
Ahmad Budiyono \\ Program Studi Pendidikan Agama Islam, STIT al Urwatul Wutsqo - Jombang \\ onobudi.stituw@gmail.com
}

\begin{abstract}
Behavior education is important to learn not only in formal but also in non formal education, such as in family. The behavior concept has been formulated by many schoolars. One of them was Imam al Ghazali. The researcher raises the the al Ghazali thought who is classic figure known as theologist, philoshopher and sufi from sunni. Behavior education as explained in Ihya' Ulumuddin book is prioritized to formulate students' moral. He discussed some such behavior education, as moral to them selves that is eating and drinking, moral respect to visitors, in trading, in socialization. The morals as if refer to material, but it refers to the future. To implement those moral correctly, it needs some methods for example habitual, modelling, and story telling.
\end{abstract}

Keyword: Islamic education, moral, Imam al Ghazali

\section{PENDAHULUAN}

Pendidikan dalam arti luas adalah segala pengalaman belajar yang dilalui peserta didik dengan lingkungan dan sepanjang hayat. Pendidikan dalam batasan yang sempit adalah proses pembelajaran yang dilaksanakan di lembaga pendidikan formal (madrasah/sekolah). ${ }^{1}$

Muhammad Muntahibin Nafis, menyatakan bahwa pendidikan yang amat penting itu tujuanya harus diambil dari pandangan hidup. sehingga jika pendidikan Islam, maka tujuan pendidikannya harus diambil dari Islam pula.

Jadi pada dasarnya tujuan pendidikan Islam sejalan dengan tujuan misi Islam itu sendiri, yaitu mempertinggikan nilai-nilai akhlak hingga mencapai tingkat akhlaqul al-karimah ${ }^{2}$. Masalah akhlak adalah masalah yang sangat penting dalam kehidupan, pendidikan agama Islam merupakan kebutuhan yang dapat digunakan landasan baik dalam kehidupan keluarga

\footnotetext{
${ }^{1}$ Ramayulis, Ilmu Pendidikan Islam, (Jakarta: Kalam Mulia, 2008), 17-18

${ }^{2}$ Muhammad Muntahibun Nafis, Ilmu Pendidikan Islam, ( Yogyakarta: Teras, 2011), 58-60
} 


\section{Ahmad Budiyono}

maupun kehidupan berbangsa dan bernegara. Pendidikan akhlak merupakan masalah yang dinamik, merupakan isu yang selalu muncul (recurrent issues) di Negara-Negara maju maupun yang sedang berkembang. pendidikan akhlak di selenggarakan untuk menyiapkan sumber daya manusia yang berlandaskan agama. Di samping itu, lebih ideal lagi yaitu untuk mencerdaskan bangsa dalam rangka mengangkat harkat dan martabat mereka sebagai manusia.

Apabila kita mengamati berbagai fenomena kerusakan moral bukan hanya muncul di tengah orang-orang yang tidak berpendidikan, tapi justru datang dan terjadi dari kalangan orang yang terpelajar. Dikalangan para pelajar dan mahasiswa, kita sangat sering disuguhi berita tentang berbagai jenis kenakalan, seperti tawuran antar pelajar, tindakan anarkhis dalam demontrasi, penyalahgunaan narkoba, pergaulan bebas, perilaku penyimpangan seksual, pesta minuman keras dan perilaku negatif yang lain. Di kalangan para pejabat dan elit politik, kita juga sering disuguhi berita tentang perilaku negatif, misalnya: KKN (korupsi, kolusi, dan nepotisme),

Akhlak merupakan bagian dari sistem ajaran Islam, akhlak juga telah menjadi disiplin ilmu pengetahuan agama yang sejajar dengan disiplin ilmu keislaman lainya. sebagai suatu disiplin ilmu keislaman lainnya, akhlak bukan menjadi kurikulum wajib yang diajarkan di pesantren di wilayah nusantara sejak sekitar abad ke 19 samapai sekarang. ${ }^{3}$

Dalam hal ini dapat dilihat peran teori fitrah dalam pembentukan manusia yang paripurna, sesuai dengan tujuan pendidikan Islam yaitu untuk mendidik warga negara Mu'min dan masyarakat muslim agar dapat merealisasikan 'ubudiah kepada Allah semata. Dan dengan

\footnotetext{
${ }^{3}$ Muhammad Achjar, Risalah Akhlak Dasar teoritis dan Praktis Etika Islam, (Surabaya: Sunan Ampel Pres, 2010), iii
} 


\section{Konsep Pendidikan Islam Mengenai Akhlak Perspektif Al Ghazali (Kajian Kitab Ihya' Ulumuddin)}

terealisasikannya atau termanifestasikan nilai penghambaan seseorang dalam kehidupannya, maka ia akan menjadi individu yang baik dan ber'akhlaqul al-karimah. ${ }^{4}$

Akan tetapi, realita yang terjadi dilapangan tidak demikian. Perkembangan dan kecanggihan ilmu pengetahuan dan teknologi informasi yang luar biasa, seharusnya juga disertai dengan perhatian terhadap pendidikan, khususnya pendidikan moral. Yang terjadi sekarang justru sebaliknya, adanya krisis pendidikan karakter (akhlak). Hal ini sangat membahayakan bagi kelangsungan hidup manusia. Bahaya dari krisis ini melebihi krisis pangan, energi, politik dan krisis yang lain.

Dari problematika di atas, penulis ingin mengangkat pemikiran seorang figur klasik yaitu al-Ghazali. Yang dikenal sebagai seorang teolog, filosof, dan sufi dari aliran Sunni, dalam hal ini kami tertarik untuk mengangkat kembali pemikiran imam al Ghazali tentang pendidikan akhlak dalam kitab Ihya' Ulumuddin yang mana dalam kita itu diterangkan bagaiamana al Ghazali mengajarkan sebegitu detail tentang akhlak. Yaitu akhlak kepada Allah dan Akhlak Kepada diri sendiri dan orang lain yang mana dalam akhlak kepda diri sendiri dan orang lain seperti akhlak dalam makan dan minum, menerima tamu, berdagang, bergaul dan keNabian

\section{PEMBAHASAN}

\section{Pengertian Pendidikan Akhlak}

Pendidikan akhlak merupakan permasalahan utama yang selalu menjadi tantangan manusia dalam sepanjang sejarahnya. Sejarah bangsa-bangsa baik yang diabadikan dalam alqur'an seperti kaum 'Ad, Samud, Madyan, dan Saba'. menunjukkan bahwa suatu bangsa akan

\footnotetext{
${ }^{4}$ Abuddin Nata, Filsafat Pendidikan Islam Edisi Baru (Jakarta: Gaya Media Pratama, 2005), 211-212
} 


\section{Ahmad Budiyono}

kokoh apabila akhlaknya kokoh, dan sebaliknya sesuatu bangsa akan runtuh apabila akhlaknya rusak. $^{5}$

Pendidikan akhlak saat ini agaknya menjadi sebuah tuntutan yang mendesak untuk dilakukan. Hal ini dilatar belakangi oleh dua kondisi. Pertama, kondisi bangsa Indonesia yang seakan-akan telah kehilangan akhlak atau karakter yang telah dibangun berabad-abad. Dimana, keramahan, tenggang rasa, kesopanan, rendah hati, suka menolong, solidaritas sosial dan lain sebagainya yang merupakan jati diri bangsa seolah olah hilang begitu saja. Kedua, kondisi lingkungan sosial kita belakangan ini diwarnai oleh maraknya tindakan barbarisme, vandalisme, baik fisik maupun nonfisik, hilangnya keteladanan pemimpin, sering terjadinya pembenaran politik dalam berbagai permasalahan yang jauh dari kebenaran universal, larutnya semangat berkorban bagi bangsa dan negara. Dapat dikatakan, krisis akhlak yang menimpa bangsa semakin menjadi-jadi, hal ini ditandai dengan maraknya tindak asusila, kekerasan, pembunuhan, perjudian, pornografi, meningkatnya kasus kenakalan remaja, penyalahgunaan narkoba, minum-minuman keras, serta menjalarnya penyakit sosial lain yang makin kronis.

\section{Pendidikan Islam Dalam Upaya Membentuk Akhlak}

1. Klasifikasi Akhlak

Ada dua jenis akhlak dalam Islam, Akhla $<$ kul kar $<$ imah (akhlak terpuji) yaitu akhlak yang baik dan benar menurut syariat Islam ${ }^{6}$, dan Akhla $<k u l$ Mazm $<$ umah (akhlak buruk) ialah akhlak yang tidak baik dan tidak benar menurut Islam. ${ }^{7}$ Dalam perkembagan zaman dan teknologi yang sangat maju dan pesat, banyak terjadi hal-hal yang tidak diinginkan

\footnotetext{
${ }^{5}$ Suwito, Filsafat Pendidikan Akhlak Ibnu Miskawaih, (Jogjakarta; Belukar, 2004), 21

${ }^{6}$ Tim Penyusun MKD IAIN Sunan Ampel Surabaya, Akhlak Tasawuf, (Surabaya: Sunan Ampel Pres, 2011), 153

${ }^{7}$ Yatimi Abdullah, Studi Akhlak dalam Persepektif Al Qur'an, (Jakarta: Sinar Grafika Offset, 2007), 12
} 


\section{Konsep Pendidikan Islam Mengenai Akhlak Perspektif Al Ghazali (Kajian Kitab Ihya' Ulumuddin)}

yang dapat merusakan keimanan. Oleh karena itu sangat penting untuk mempelajari dan memahami kehidupan sehari-hari dalam mencapai kehidupan yang bahagian dan tertram. ${ }^{8}$

2. Faktor-Faktor yang Mempengaruhi Pembinaan Akhlak

a) Faktor dari luar dirinya

Lingkungan adalah ruang dan waktu yang menjadi tempat eksistensi manusi. Dalam konsep ajaran Pendidikan Agama Islam, lingkungan yang baik adalah lingkungan yang diridhoi oleh Allah dan Rasulullaah. ${ }^{9}$ Adapun lingkungan yang mempengaruhi pembinaan akhlak yaitu :

(1)Lingkungan Keluarga

Lingkungan keluarga menjadi tolak ukur keberhasilan anak dalam pendidikan. Oleh karena itu, terutama orang tua yang memikul tanggung jawab terbesar dalam pendidikan anak, sepatutnya mengembangkan potensi dirinya melalui keikutsertaanya dalam acara-acara yang bermanfaat, misalnya, pengajian, berorganisasi, dan sebagainya. Dengan demikian ilmu pengetahuannya semakin berkembang dan memberi manfaat untuk pengembangan pendidikan Islam dalam lingkungan keluarga. $^{10}$

(2)Lingkungan Sekolah

Lingkungan sekolah terdiri atas tempat belajar dan mengajar, para pendidik dan anak didik, karyawan sekolah, alat-alat dan fasilitas sekolah. Lingkungan sekolah juga harus menjamin kelancaran komunikasi anak didik dengan semua pihak sekolah

\footnotetext{
${ }^{8}$ Ibid., 55

${ }^{9}$ Beni ahmad Saebani. al, Ilmu Pendidikan Islam (Bandung : Pustaka Setia, 2009), 262.

${ }^{10}$ Hasan basri. al, Ilmu Pendidikan Islam (jilid II) (Bandung : Pustaka Setia, 2010), 115.
} 


\section{Ahmad Budiyono}

untuk mempermudah hubungan interaksional anak didik dengan semua pihak sekolah yang berkaitan dengan kepentingan pembelajaranya.

Ilmu Pendidikan Islam yang dapat dikembangkan dalam lingkungan sekolah, salah satunya adalah ilmu tentang kebersihan lingkungan sekolah, kebersihan jasmani dan rohani, kebersihan niat menuntut ilmu, dan usaha-usaha pemeliharaan lingkungan sekolah yang islami. ${ }^{11}$

(3)Lingkungan Masysrakat

Masyarakat merupakan lingkungan ketiga dalam mengembangkan aktivitas hidup anak. Disamping dipengaruhi oleh faktor pembawaan, perilaku seseorang anak juga dipengaruhi oleh faktor lingkungan. Masyarakat turut memikul tanggung jawab dalam pendidikan. Masyarakat besar pengaruhnya dalam memberi arah terhadap pendidikan anak, terutama para pemimpin masyarakat atau penguasa yang ada di dalamnya.

b) Faktor dari dalam dirinya

(a) Spiritual (agama)

Triantono mengatakan setiap setiap anak memiliki kebutuhan spiritual yang harus di penuhi dalam kehidupan. Kebutuhan dasar keagamaan ini (spiritual needs) jika terpenuhi akan menimbulkan keadaan damai, aman, dan tentram dalam kehidupan. $^{12}$

(b) biologis

\footnotetext{
${ }^{11}$ Ibid., 122.

${ }^{12}$ Trianto Safarima, Spritual Intelegence, Metode Pengembagan Kecerdasar Spiritual Anak, (Yogyakarta: Graha Ilmu, 2007), 86
} 


\section{Konsep Pendidikan Islam Mengenai Akhlak Perspektif Al Ghazali (Kajian Kitab Ihya' Ulumuddin)}

Kebutuhan yang bersifat fisik atau jasmani, termasuk susunan syaraf pusat (orak). Perkembagan biologis di mulai sejak dalam pembuahan, bayi, masa anakanak, remaja, dewasa dan sampai usia lanjut. Perkembangan fisik ini memerlukan makanan bergizi, halal, dan bebas dari penyakit yang membahayakan kebutuhan biologis yang baik atau menentukan sejauh mana perkembangan syaraf pusat (otak) dan kondisi organ fisik lainya. Dan masih banyak faktor yang lain seperti. insting, kepercayaan, keiginan, hati nurani, hawa nafsu. ${ }^{13}$

\section{Konsep Pendidikan Akhlak Perspektif al Ghazali dalam Kitab Ihya Ulumuddin}

Dalam pembagian akhlak al Ghazali mempunyai 4 kriteria yang harus dipenuhi untuk suatu kriteria akhlak yang baik dan buruk, yaitu: Kekuatan 'Ilmu, atau hikmah, kekuatan marah, yang terkontrol oleh akal akan menimbulkan sifat syaja'ah, kekuatan nafsu syahwat, dan kekuatan keseimbangan (keadilan), ${ }^{14}$

1. Akhlak Makan dan minum

Konsep Pendidikan akhlak mengenai tata kesopan makan, dalam Kitab Ihya' Ulumuddin di sini ada 2 bagian, yaitu:

a) Bagian Pertama: Tata krama sebelum makan itu ada tujuh macam sebagaimana berikut:

(1)Mengetahuai keadaan makanan

Makanan itu setelah keadaan halal pada dirinya. Baik dalam segi usaha, sesuai dengan sunah dan wara'. Dimana makanan itu tidak di usahakan dengan sebab yang makruh menurut syara' dan tidak dengan hukum hawa nafsu dan tidak berminyak air dalam agama yaitu menurut apa yang akan datang mengenai pengertian baik dan

\footnotetext{
${ }^{13}$ Djadmika Rahmat, Sistem Etika Islam (Surabaya : Pustaka Islami, 1987), 73.

${ }^{14}$ Al Ghazaly, Ihaya' Ulumuddin, jilid ke II, (Qairo, Mesir: Dar al-taqwa. 2000), 600
} 


\section{Ahmad Budiyono}

mutlak dalam kitab halal dan haram. ${ }^{15}$

(2)Bersuci Sebelum Makan

Dalam kitab Ihya' Ulumuddin diterangkan bahwa sebelum makan kita diwajibkan untuk wudhu sebagaimana hadits ath Thabrani dari Ibnu Abbas.

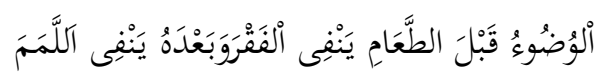

“Wudhu' Sebelum makan itu meniadakan kefakiran dan wudhu setelah makan itu meniadakan dosa kecil”. 16

Dan diriwayat lain. juga diterangkan bahwa keutamaan wudhu

(3)Tempat Makanan

Ditanya “diatas apakah kamu makan?" maka beliau menjawab "Di atas hamparan”. Dan dikatakan empat hal yang diadakan setelah Rosulullah yaitu meja makan, ayakan tepung, wijikan dan kenyang. Dan semua ini tidak dikatakan bid'ah setelah Rosulullah SAW, karena tidak setiap yang diada-adakan itu terlarang. Tetapi yang berlarangan adalah bid'ah yang berlawanan dengan sunah yang sahih, dan hilangnya pada urusan syara' padahal ilatnya masih. ${ }^{17}$

(4)Duduk diatas hamparan

Didalam kitab Ihya' Ulumuddin di jelaskan akhlak dalam makan dan minum Minum dengan bertelentang itu makruh, sebagaimana sebuah Hadits di jelaskan sebagaiman berikut:

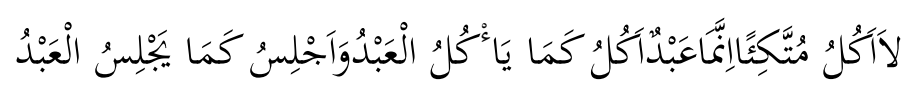
"Saya (Rosulullah) tidak makan dengan bertelentang, aku (Rosulullah) hanyalah seorang hamba yang makan sebagaimana hamba itu makan, dan aku duduk sebagaimana aku duduk". ${ }^{18}$

\footnotetext{
${ }^{15}$ H. Moh. Zuhri, et al, Ihya' Ulumuddin. Jilid III Terj, (Semarang : CV. Asyifa', 2003), 4

${ }^{16}$ Dr. Badawi Thabah, Ihya' Ulum Ad Dl-Din Lilimam Al Aghozali. Juz II, (Sigapura, Al Haramain, tt), 3

${ }^{17} \mathrm{H}$. Moh. Zuhri, et al. Ihya' Ulumuddin. Jilid III Terj, 6

${ }^{18}$ Dr. Badawi Thabah, Ihya' Ulum Ad Dl-Din Lilimam Al Aghozali. Juz II, 4
} 


\section{Konsep Pendidikan Islam Mengenai Akhlak Perspektif Al Ghazali (Kajian Kitab Ihya' Ulumuddin)}

Minum dengan bertelentang itu makruh, makan dengan tidur dan bertelentang juga makruh, kecuali makan biji-bijian yang dapat di pindahkan. Diriwayatkan dari Ali Karomallahu Wajhah "bahwasanya dia makan roti diatas piring besar sambil berbaring, Dan ada yang mengatakan membujur pada perutnya. Dan bangsa arab juga melakukanya". 19

(5)Niat Makan

Dengan makan ia berniat untuk menjaga ketaatan kepada Allah Ta'ala dimana dengan makan itu agar ia menjadi orang ta'at. Dan dengan makan itu ia tidak mencari keenakan dan kenikmatan. Ibrahim bin Syaibah berkata: "Sejak delapan puluh tahun saya tidak makan sesuatu karena syahwat." Oleh karena niat ini maka ia memecahkan syahwat dan mengutamakan qona'ah secara Luas. ${ }^{20}$ Rosulullah SAW, bersabda:

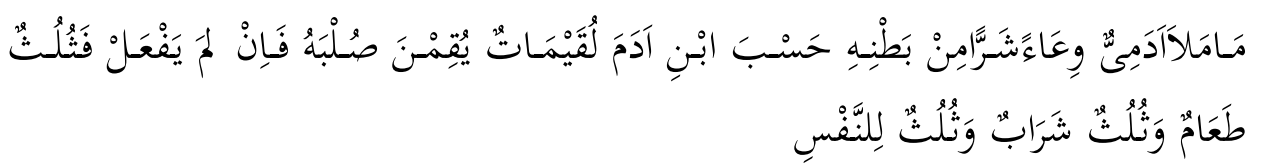

"Tidaklah anak adam (mansuia) mengisi tempat yang lebih buruk dari pada perutnya. Cukuplah anak adam (manusia) dengan beberapa suap yang mengakkan tulang belakangnya. Jika ia tidak melakukannya maka sepetiga isi perutnya makan, sepertiga isi perutnya itu minuman dan sepertiga isi perutnya itu untuk nafas ",21

(6)Ridho atas Apa yang Ada

Yang di maksud ridho disini ialah ridho atas rizki yang ada dalam makanan yang hadir (dihidangkan), dan ia tidak bersungguh-sungguh dalam mencari kenikmatan, mencari tambahan dan menanti lauk pauk. Dan apabila sudah waktunya

\footnotetext{
${ }^{19}$ Ibid., 4

${ }^{20} \mathrm{H}$. Moh. Zuhri, et al. Ihya' Ulumuddin. Jilid III Terj, 7-8

${ }^{21}$ Dr. Badawi Thabah, Ihya' Ulum Ad Dl-Din Lilimam Al Aghozali. Juz II, 4
} 


\section{Ahmad Budiyono}

makan dan sholat isya' maka mulailah dengan makan malam sebagaimana sabda Nabi $\mathrm{SAW}^{22}$ :

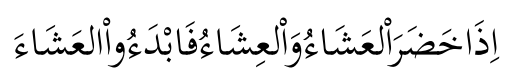

“Apabila datang makan malam dan sholat isya' maka mulailah dengan makam malam",3

Jadi apabila makanan datang dan sholat didirikan sedangkan dalam mengediamkan itu menjadikan makanan itu dingin atau mengacaukan urusanya maka mendahulukan itu lebih disukai ketika luas/lapang waktu.

(7)Bersama-sama dalam makan

Dalam kitab Ihya' Ulumuddin disini dijelaskan, alangkah baiknya maka bersama-sama. Sebagaiamana Hadits Nabi :

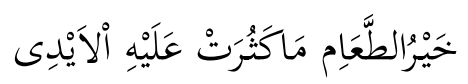

"Sebaik-baik makan adalah makanan yang yang paling banyak tangan padanya",24

b) Bagian kedua: tata kesopanan dalam makan.

Tata kesopanan makan yang di maksud dalam kita Ihya' Ulumuddin yaitu: a). Memulai dengan menbaca basmalah, b). Tidak boleh mencela sesuatu yang di makan, c). Jangan meniup makanan yang panas, d). Memperbanyak minum ditengah-tengah makan apabila ia terhenti. Adapun tata kesopanan minum yaitu mengambil gelas dengan tangan kanannya dan mengucapkan dengan bismilaah dan meminum dengan menghisab. Jangan minum dengan berdiri dan tidak pula dengan berbaring. ${ }^{25}$

\footnotetext{
${ }^{22}$ H. Moh. Zuhri, et al. Ihya' Ulumuddin. Jilid III Terj, 9

${ }^{23}$ Dr. Badawi Thabah, Ihya' Ulum Ad Dl-Din Lilimam Al Aghozali. Juz II, 4

${ }^{24}$ Ibid, 5

${ }^{25} \mathrm{H}$. Moh. Zuhri, et al. Ihya' Ulumuddin. Jilid III Terj, 10-13
} 


\section{Konsep Pendidikan Islam Mengenai Akhlak Perspektif Al Ghazali (Kajian Kitab Ihya' Ulumuddin)}

2. Akhlak Menerima Tamu

Dalam kitan Ihya' Ulumuddin disini dijelaskan tentang akhlak bertamu atau menerima tamu. Di sisni dijelaskan bahwa dalam menerima tamu kita di anjurkan menghormati tamu. Akan tetapi dalam menghormati tamu itu tidak mempersulitkan diri kita. Sebagaimana Rosulullah SAW. Telah bersabda.

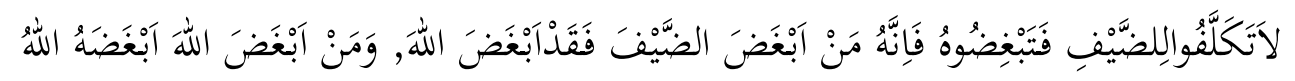
"Jangan engkau memaksa diri untuk menghormati tamu hingga kamu membencinya, sebab barang siapa yang membeci tamu, maka ia pun memmbenci Allah. Sedangkan siapa yang membenci Allah maka Allah Pun Membencinya",26

3. Akhlak Berdagang

Pendidikan akhlak dalam berdagang atau tata kesopanan (akhlak) berdagang ada beberapa aspek. Seperti perindustrian dan berbagai usaha, dan sunahnya dalam ini dijelaskan dalam lima bab yaitu:

a) Mengenal keutamaan usaha dan dan dorongan atasnya.

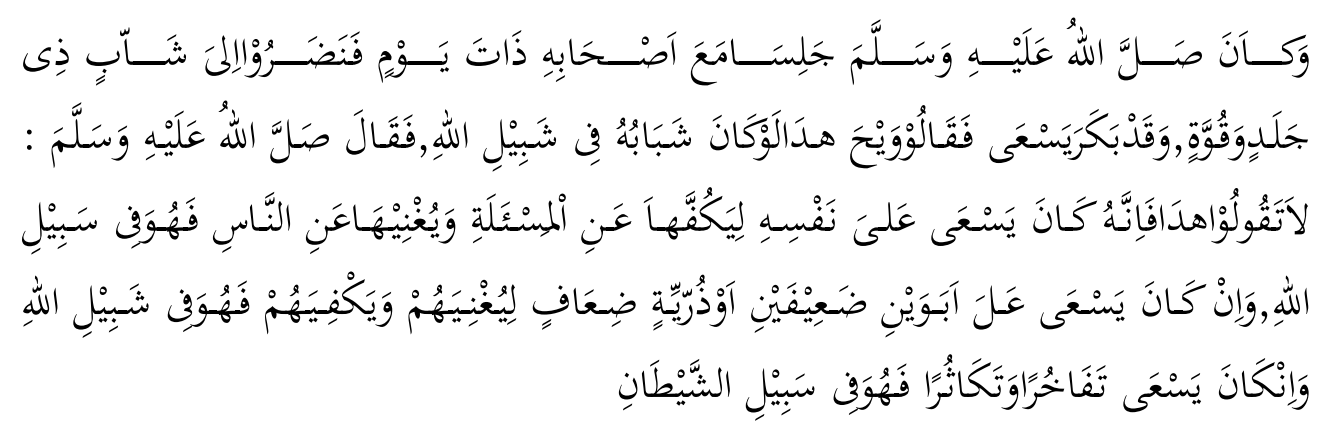

"Pada suatu hari beliau Rosulullah SAW duduk bersama sahabatnya. Mereka melihat kepada seorang pemuda yang mempunyai ketabahan dan kekuatan. Ia pagi-pagi telah berusaha, maka mereka berkata: "celakalah pemuda ini. Seandainya kemudahan (dipergunakan) dijalan Allah”. Maka beliau bersabda: "janganlah kau ucapkan ini, karena jika ia berusaha untuk dirinya dan untuk mencegah dari minta-minta dan tidak membutuhkan dari manusia maka ia di jalan Allah. Jika ia berusaha untuk kedua orang tuanya yang lemah atau keturunan yang lemah agar mereka kaya dan mencukupi mereka maka ia dijalan Allah. Dan jika ia berusaha karena bangga diri dan

${ }^{26}$ Dr. Badawi Thabah, Ihya' Ulum Ad Dl-Din Lilimam Al Aghozali. Juz II, 12 


\section{Ahmad Budiyono}

banyak-banyak maka ia di jalan syaithan. ${ }^{27}$

b) Mengenai ilmu jual beli dan muamalah secara benar

Ilmu (aqad) itu banyak, akan tetapi enam akad ini tidak bisa lepas dari padanya yaitu : jual beli, riba, pesanan (salam), sewa menyewa, bagi laba dan syirkah, maka kami uraikan syarat-syaratnya:

(1)Akad Jual beli. orang yang beraqad, sesuatu yang diaqadkan, lafad.

(2)Riba. Allah melarang dengan keras riba, kecuali pada makanan. Dan wajib tukang tukar untuk mejaga diri dari nasiah dan fadhl.

(3)Pesanan (salam). Dalam aqad (salam) pesana seorang hendaknya menjaga sepuluh syarat. Modal diketahui terhadap mitsilnya, menyerahkan modal dalam majlis aqad sebelum berpisah. mengetahui jenis dan sifat barang yang dipesan. dihabiskan penyifatan hal-hal yang menerima dapat disifati sehingga tidak ada sifat yang padanya berbeda harga. Menentukan waktu. Sesesatu yang dipesan termasuk sesuatu yang dapat diserahkan pada waktunya. Menyebutkan tempat penyerahan. Tidak digantung pada sesuatu yang ditentukan. Tidak memesan sesuatu yang indah. Tidak memesan makanan apabila modalnya itu makanan.

(4)Sewa menyewa. Sewa itu mempunyai dua rukun yaitu ongkos dan manfaat.

(5)Qirdh. Yaitu bagi laba, dalam qirad ada 3 rukun yaitu modal, laba, pekerjaan yang menjadi kewajiban pekerja. Syirkah atau persyekutuan ini ada tiga macam diantaranya batal. Empat macam itu adalah Syirkatul Fawadhah, Syirkah abdan (badan), syirkah wujuh (muka), syirkah 'inam.

c) Mengenai penjelasan adil dalam mu'amalah

Ketahuilah bahwa mu'amalah itu kadang-kadang berlaku atas segi dimana mufti

\footnotetext{
${ }^{27}$ Dr. Badawi Thabah, Ihya' Ulum Ad Dl-Din Lilimam Al Aghozali. Juz II, 63
} 


\section{Konsep Pendidikan Islam Mengenai Akhlak Perspektif Al Ghazali (Kajian Kitab Ihya' Ulumuddin)}

menghukumi kesalahannya. Tetapi mu'amalah itu mengandung kedzaliman (penganiayaan) yang menjadikan orang orang berbuat kemungkaran itu menerima kemungkaran Allah Ta'ala. Yang dimaksud kedholiman ada sesuatu yang menjadi madharat kepada orang lain.

Pertama, menimbun (menyimpan) makanan yang dengannya ia menanti mahalnya harga. Kedua, membuat lakunya dirham-dirham palsu ditengah-tengah uang emas dan uang perak. Ketiga, tidak memuji barang dengan sesuatu yang lain. Keempat, tidak menyembunyikan sama sekali akan cacatnya, dan sifat-sifat yang tersembunyi sedikitpun. Kelima, tidak menyembunyikan sedikitpun mengenai timbangan dan ukuranya. Keenam, dan tidak menyembunyikan harga, dimana seandainya orang bermuamalah itu mengetahui niscaya ia mencegah terhadapnya. ${ }^{28}$

d) Mengenai berbuat baik atas usaha

Adil adalah sebab keselamatan saja, keadilan bedagang seperti jalanya modal. Sedangkan berbuat baik itu adalah sebab kemenangan dan memperloleh kebahagiaan. Dalam berdagang berbuat baik ini berjalan seperti jalannya keuntungan. Derajat berbuat baik ini diperoleh dengan salah satu dari enam hal yaitu: a). Tidak menipu, b). Tidak menangguhkan tipu daya dan pembeli jika ia membeli makanan dari orang yang lemah atau fakir maka tidak mengapa ia menangguhkan tipu daya dan bersikap mudah, dan ia menjadi berbuat baik karenanya, c). Dalam memenuhi harga dan seluruh hutang-hutang, dan berbuat baik padanya, d). Ia menfasakh (menghapus jual beli itu), e). Mengenai kesayangan pedagang kepada agamnya, mengenai sesuatu yang khusus terhadapnya dan

${ }^{28}$ H. Moh. Zuhri, et al. Ihya' Ulumuddin. Jilid III Terj, 218-263 


\section{Ahmad Budiyono}

merata kepada akhiratnya. ${ }^{29}$

Janganlah kamu melupakan bagaianmu di dunia untuk akhirat. Dan didunia ini diusahakan kebaikan-kebaikan. Hanya sempurna kesayangan pedagang terhadap agamanya dengan memelihara tujuh hal yaitu: a). Baik niat dan akidah dalam memulai perdagangan, b). Bermaksud untuk melaksanakan salah satu fardhu kifayah didalam pekerjaan dan perdagangan, c). Pasar dunia tidak menghalangi pasar akhirat. d). Tidak membatasi (mencukupkan) pada hari ini, tetapi ia terus menetapi dzikir kepada Allah. e). Ia tidak sangat laba terhadap pasar perdagangan. f). Bahwa ia tidak mencukupkan diri untuk menjauhi barang haram tetapi ia memelihara tempat-tempat syubhat dan tempat dugaan keraguan, g). Mengawasi seluruh jalan pergaulanya bersama seseorang dari orang-orang yang mempergaulinya, karena sesungguhnya ia adalah pengawas dan perhitungan. $^{30}$

4. Akhlak Bergaul (berteman)

a) Hak-Hak Orang Muslim

Hak-hak orang muslim adalah agar kamu memberi salam apabila berjumpa dengannya. Mendatagi undangan apabila di undang, membaca do'a apabila mendengarkan bersin. Menasehati apabila ia minta di nasehati. Semua itu telah disebutkan dalam hadits-hatis dan atsar-atsar ${ }^{31}$. Anas ra. Telah meriwayatkan dari Rosulullah:

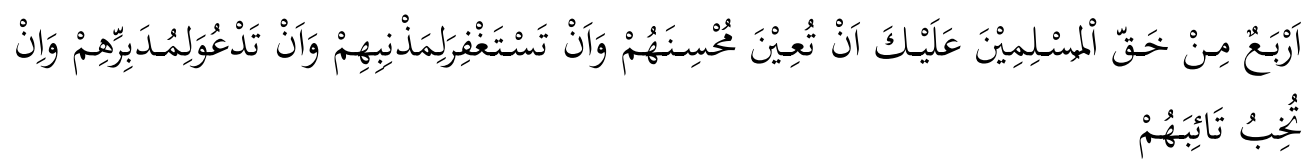

"Empat macam hak para muslim atas kamu adalah agar kamu menolong

\footnotetext{
${ }^{29}$ H. Moh. Zuhri, et al. Jilid III Terj, Loc. Cit, 264-276

${ }^{30}$ H. Moh. Zuhri, et al. Ihya' Ulumuddin. Jilid III Terj, 278-293

${ }^{31}$ H. Moh. Zuhri, et al, Ihya' Ulumuddin. Jilid IV Terj, (Semarang : CV. Asyifa', 2003),3-4
} 


\section{Konsep Pendidikan Islam Mengenai Akhlak Perspektif Al Ghazali (Kajian Kitab Ihya' Ulumuddin)}

mereka yang berbuat baik kamu memohonkan ampun kepada mereka yang berdosa, kamu berdo'a bagi yang telah lalu dan kamu mencintai mereka yang bertaubat",32

Dalam sebuah hadits lain disebutkan bagaiamana nabi memberikan pelajaran

kepada kita, terutama akhlak kita kepada anak kecil. Sebagaimana beliau Rosulullah di minta mendo'akannya:

Didatang kepada Rosulullah SAW, anak kecil agar beliau berdo'a baginya dengan barokah agar nama kepadanya, maka beliau mengambilnya lalu meletakan dipangkuanya maka kadang-kadang anak kecil itu kencing dan berteriaklah sebagaimana orang melihatnya lalu beliau bersabda: janganlah kamu putuskan kencing anak kecil itu. Beliau membiarkanya sampai selesai kecingnya. Dan beliau menyampaikan kegembiraan keluarga beliau tentang anak kecil itu agar mereka tidak melihat bahwa beliau merasa sakit dengan kencingnya lalau apabila mereka telah berpergian. Maka beliau mencuci pakaianya setelah kepergian mereka." 33

b) Hak-Hak Bertetangga

Sesungguhnya bertentangga itu menentukan hak apa yang telah ditentukan oleh saudara Islam tetangga orang muslim berhak apa yang menjadi hak orang muslim dan tambahan. Rosulullah SAW bersabda:

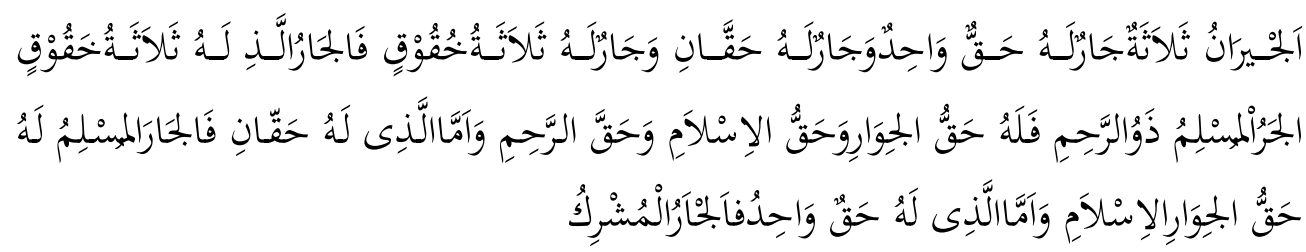

"Tetangga itu ada tiga yaitu tetangga yang mempunyai satu hak, tetangga yang mempunyai dua hak, dan tetangga yang mempunyai tiga hak. Tetangga yang mempunyai tiga hak yaitu : hak tentang tetangga muslim yang mempunyai ikatan kerabat maka baginya hak bertetangga, hak Islam dan hak kerabat. Adapun tetangga yang mempunyai dua hak yaitu tetangga muslim. Baginya yang bertetangga dan hak Islam. Adapun tetangga yang mempunyai satu hak yaitu tetangga musyrik (bukan Muslim),"34

Hak tetangga adalah memuliakannya dengan memberi salam, tidak

memanjangkan pembicaraan dengannya dan tidak memperbanyak pertanyaan

\footnotetext{
${ }^{32}$ Dr. Badawi Thabah, Ihya' Ulum Ad Dl-Din Lilimam Al Aghozali. Juz II, 191

${ }^{33}$ H. Moh. Zuhri, et al, Ihya' Ulumuddin. Jilid IV Terj,16-17

${ }^{34}$ Dr. Badawi Thabah, Ihya' Ulum Ad Dl-Din Lilimam Al Aghozali. Juz II, 211
} 


\section{Ahmad Budiyono}

keadaanya. Menjeguknya diwaktu sakit menghibur diwaktu menerima musibah. Berdiri bersama dalam ta'ziah. Mengucapkan selamat kepadanya diwaktu gembira. dll. ${ }^{35}$

c) Hak-Hak Orang Tua dan Anak

Tidak samar apabila hak kerabat dan famili menjadi kuat famili yang lebih khusus dan lebih melekat adalah hubungan kelahiran (hubungan anak dengan kedua orang tuanya) maka beratnya hak di dalam hubungan kelahiran itu berlipat ganda.

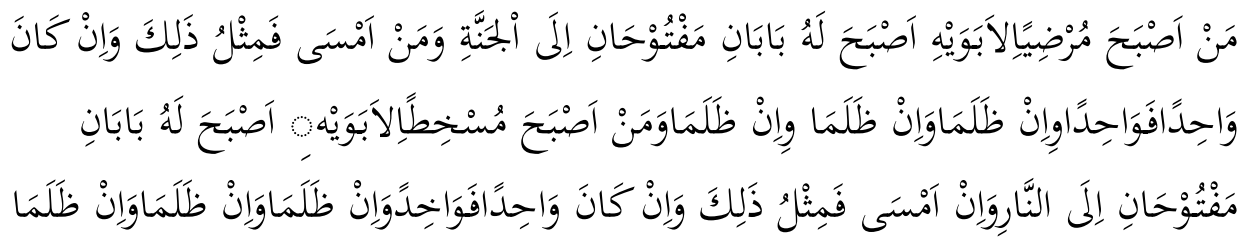

"Barang Siapa pagi-pagi menyenangkan kedua orang tua maka baginya dua pintu yang terbuka menuju surga. Barang siapa yang sore-sore berbuat demikian. Maka baginya seperti itu dan kalau orang tua seorang maka ia memperoleh satu pintu meskipun keduanya berbuat aniaya . meskipun keduanya berbuat aniaya dan meskipun keduanya berbuat aniaya. Dan barang siapa yang pagi-pagi membuat aniaya kepada kedua orang tua. Maka baginya kedua pintu yang terbuka yang menuju keneraka dan apabila ia sore-sore berbuat demikian. Maka baginya seperti itu. kalau seorang maka ia mendapatkan satu pintu meskiupun keduanya menganiaya dan meskipun keduanya menganiaya, 36

Dari paparan hadits diatas, kita disuruh untuk berbuat baik kepada kedua orang

tua. Bagaiamana akhlak kita kepada orang tua. Sebuah hadits menjelaskan bahwa ada seseorang laki-laki berhijrah maka baginda Rosulullah memerintahkan kepada mereka untuk kembali dan meminta ijin kepada orang tua. Apabila orang tuamu mengijinkan maka pergilah, jika orang tuamu tidak mengijinkan maka berjihadlah semampumu.

\section{Kesimpulan}

Pendidikan Islam berperan sebagai pengendali tingkah laku atau perbuatan yang

\footnotetext{
${ }^{35}$ H. Moh. Zuhri, et al, Ihya' Ulumuddin. Jilid IV Terj, 76-80

${ }^{36}$ Dr. Badawi Thabah, Ihya' Ulum Ad Dl-Din Lilimam Al Aghozali. Juz II, 216
} 


\section{Konsep Pendidikan Islam Mengenai Akhlak Perspektif Al Ghazali (Kajian Kitab Ihya' Ulumuddin)}

terlahir dari sebuah keinginan yang berdaran emosi. Jika ajaran agama sudah terbiasa dijadikannya sebagai pedoman dalam kehidupannya sehari-hari dan sudah ditanamkannya sejak kecil, tingkah lakunya akan lebih terkendali dalam menghadapi segala keinginankeinginannya yang timbul pada diri manusia.

Jadi pendidikan Islam sangat erat hubungannya dengan pendidikan akhlak yaitu bertujuan untuk membentuk manusia yang berbudi pekerti yang luhur dan bertangung jawab. Dengan kata lain bahwa pendidikan Islam bertujuan untuk mencetak manusia yang mempunyai kesempurnaan (insan kamil) dalam kepribadianya Sebagaimana Hadits Nabi :

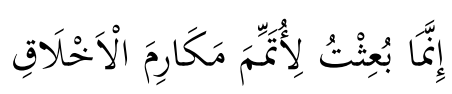

Artinya: "Sesungguhnya aku diutus semata-mata untuk menyempurnakan kemuliaan akhlak". (H.R. al-Hakim, dari Abu Hurairah)

Pendidikan akhlak menurut al Ghazali dalam kitab Ihya' Ulumuddin, yaitu lebih menekankan kepada pembentukan akhlak peserta didik, al Ghazali membahas beberapa pendidikan akhlak antara lain akhlak kepada diri sendiri dan orang lain yaitu akhlak makan dan minum, akhlak dalam menerima tamu, akhlak dalam berdagang, akhlak dalam bergaul (berteman). Dari semua aspek akhlak tersebut, seakan akan mengarah kepada keduniawian saja, akan tetapi kesemua itu mengarah kepada akhlak ukhrowi. Dalam upaya pembembentukan akhlak diatas ada beberapa metede agar kesemua itu berjalan dengan seimbang yaitu metode pembiasaan, metode suri teladan, metode kisah atau cerita.

\section{Daftar Pustaka}

Abdullah, Yatimi. Studi Akhlak dalam Persepektif Al Qur'an. Jakarta: Sinar Grafika Offset, 2007.

Abuddin Nata, Filsafat Pendidikan Islam Edisi Baru. Jakarta: Gaya Media Pratama, 2005.

Achjar, Muhammad. Risalah Akhlak Dasar teoritis dan Praktis Etika Islam. Surabaya: Sunan Ampel Pres, 2010.

Ahmad Saebani, Beni. et al. Ilmu Pendidikan Islam. Bandung: Pustaka Setia, 2009. 


\section{Ahmad Budiyono}

Al Ghazaly. Ihaya’ Ulumuddin, jilid ke II. Qairo Mesir: Dar al-taqwa, 2000.

Basri, Hasan. al. Ilmu Pendidikan Islam (jilid II). Bandung: Pustaka Setia, 2010.

Nafis, Muhammad Muntahibun. Ilmu Pendidikan Islam. Yogyakarta: Teras, 2011.

Rahmat, Djadmika. Sistem Etika Islam. Surabaya: Pustaka Islami, 1987.

Ramayulis. Ilmu Pendidikan Islam. Jakarta: Kalam Mulia, 2008.

Safarima, Trianto. Spritual Intelegence, Metode Pengembagan Kecerdasar Spiritual Anak. Yogyakarta: Graha Ilmu, 2007.

Suwito, Filsafat Pendidikan Akhlak Ibnu Miskawaih. Jogjakarta; Belukar, 2004.

Thabah, Dr. Badawi. Ihya' Ulum Ad Dl-Din Lilimam Al Aghozali. Juz II. Sigapura: Al Haramain, tt.

Tim Penyusun MKD IAIN Sunan Ampel Surabaya. Akhlak Tasawuf. Surabaya: Sunan Ampel Pres, 2011.

Zuhri, H. Moh. et al. Ihya' Ulumuddin. Jilid III Terj. Semarang: CV. Asyifa', 2003.

Ihya'Ulumuddin. Jilid IV Terj. Semarang: CV. Asyifa', 2003. 